\title{
El Alto: una ficción política
}

El Alto: une fiction politique

El Alto: a political fiction

\section{Franck Poupeau}

\section{OpenEdition}

\section{Journals}

Edición electrónica

URL: http://journals.openedition.org/bifea/2063

DOI: $10.4000 /$ bifea.2063

ISSN: 2076-5827

\section{Editor}

Institut Français d'Études Andines

\section{Edición impresa}

Fecha de publicación: 1 agosto 2010

Paginación: 427-449

ISSN: 0303-7495

\section{Referencia electrónica}

Franck Poupeau, «El Alto: una ficción política », Bulletin de l'Institut français d'études andines [En línea], 39 (2) | 2010, Publicado el 01 febrero 2011, consultado el 06 noviembre 2020. URL : http:// journals.openedition.org/bifea/2063; DOI : https://doi.org/10.4000/bifea.2063

Les contenus du Bulletin de l'Institut français d'études andines sont mis à disposition selon les termes de la licence Creative Commons Attribution - Pas d'Utilisation Commerciale - Pas de Modification 4.0 International. 


\title{
El Alto: una ficción política
}

\author{
Franck Poupeau*
}

\section{Résumé}

Desde inicios de los años 2000, la ciudad de El Alto se ha vuelto el símbolo de una Bolivia rebelde, popular y autoorganizada, donde se manifestaría más que en cualquier otro lugar, el renacer de las luchas indígenas. Si esta visión tiene que ser considerada como parte del objeto estudiado, no puede ser aceptada tal cual. Desde su fundación y crecimiento a principios del siglo XX, esta ciudad periférica, que obtuvo su independencia administrativa en los años 1980, siempre ha cumplido una función económica en relación con la sede del gobierno boliviano, la ciudad de La Paz: transportes, artesanía y comercio han hecho de El Alto la segunda ciudad del país, y uno de sus ejes de desarrollo. Se acompaña de la creación de identidades específicas, que no remiten a una «indigenización de la modernidad» (Sahlins) sino a una relación «moderna» (y bastante nueva) con la tradición, en la cual se mezclan elementos heredados de los pueblos «originarios» y creaciones culturales y políticas locales.

Palabras clave: desigualdades socioespaciales, espacios urbanos, identidades sociales, indigenismo

\section{El Alto : une fiction politique}

\section{Résumé}

Depuis le début des annés 2000, la ville d'El Alto est devenu le symbole d'une Bolivie rebelle, populaire et auto-organisée où se manisfesterait, plus que partout ailleurs, le renouveau des luttes indigènes. Si cette vision doit être considérée comme faisant partie de l'objet d'étude, elle ne peut être acceptée comme telle. Depuis sa création et son développement, au début du XXème siècle, cette ville périphérique qui a obtenu son indépendance administrative dans les années 1980, a toujours eu une fonction économique face au siège du gouvernement bolivien, la ville de La Paz : transports, artisanat et commerce ont fait d'El Alto la seconde ville du pays et l'un de ses axes de développement. Ce phénomème s'accompagne de la création d'identités spécifiques, qui renvoie moins à une «indigénisation de la modernité» (Shalins) qu'à une relation «moderne» (et trés récente) avec la tradition, mélangeant des éléments hérités des peuples «d'origine» avec des créations culturelles et politiques locales.

* Chercheur au CSU/CRESPPA -UMR7217 CNRS. Chercheur associé à I'Institut français d'Études andines (UMIFRE 17 -CNRS/MAEE). Directeur de recherche associé à l'Institut des hautes études de I'Amérique latine. E-mail: franck.poupeau@gmail.com 
Mots clés : inégalités sociologiques et spaciales, espaces urbains, identités sociales, indigénisme

\title{
El Alto: a political fiction
}

\begin{abstract}
Since the beginning of the 2000's, the city of El Alto has emerged dramatically on the Bolivian political scene. It has become the incarnation and the symbol of popular insurrection against neoliberal governments with a popular national orientation. El Alto serves as the Aymara face (supposed to be more authentic) of social movements. This political imaginary can be considered as socially based, because it is part of the definition of the city and of the identity of its inhabitants, and part of the object of study. After a quick look at the genesis and the socioeconomic structures of the city, in order to reveal the social functions of this political image, this article will examine how the notion of what Marshall Sahlins called the indigenization of modernity can be used to analyze the political resistance of native groups in the city, and the ambivalent incorporation of occidental culture in local contexts. El Alto shows a modern relation to traditional culture, with a coexistence of social conservatism and cultural transformation; of reproduction of inequalities and invention of new forms of expression that leads to a critical view of the communitarism and of the folk vision of Andean people.
\end{abstract}

Key words: Social and Spatial Inequalities, Social movements, Indigenization of modernity, Urban identities

El Alto, que se extiende en el Altiplano, arriba de La Paz, sede del gobierno boliviano, con aproximadamente 900000 habitantes, se convirtió en 2008 en la segunda ciudad del país después de Santa Cruz'. Su crecimiento urbano se mantiene por encima del $9 \%$ anual, tasa espectacular, sobre todo si se tiene en cuenta que se trata de una ciudad cuya fundación y expansión datan de la segunda mitad del siglo XX. Sin embargo, si El Alto atrae tanto la atención se debe menos a sus características demográficas que a su irrupción en el escenario político nacional a partir de principios de los años 2000: se constituyó en el punto de convergencia de los bloqueos a través de los cuales el movimiento aymara volvió a ponerse en escena, luego de un intervalo de dos siglos, tras el cerco de La Paz por las tropas rebeldes de Tupac Katari (Thomson, 2003). Ha sido sobre todo el epicentro de la «guerra del gas» en octubre de 2003 y de la agitación social que se produjo después, en particular durante las movilizaciones contra el consorcio Aguas del Illimani en 2004 y 2005, cuya finalidad era el restablecimiento de un servicio público de suministro de agua (Sprong, 2007; Crespo \& Sprong, 2007). En el imaginario político boliviano, El Alto encarna el símbolo de la revuelta de las masas contra los gobiernos neoliberales (Lazar, 2008), teniendo en cuenta sin

1 Según el Instituto Nacional de Estadísticas (INE), la población de Santa Cruz superaría 1,5 millones de habitantes en 2010, mientras que La Paz se quedaría con 850000 habitantes. 
embargo que, desde la llegada al poder de Evo Morales en diciembre de 2005, el movimiento «nacional popular», como lo ha calificado el sociólogo boliviano René Zavaleta (1986)2, ha venido adquiriendo un rostro cada vez más «indígena»: El Alto habría pasado a ser la «cara aymara», y por lo tanto «auténtica», de la política boliviana y de los movimientos sociales 3 . Como toda ciudad, El Alto tiene una dimensión imaginaria (Gill, 2000): de la misma manera que según Marx los revolucionarios franceses de 1789 celebraban sus sesiones vestidos con togas romanas, esta copia simbólica se expresa hoy en día en el atuendo político del indio «insurrecto»e «indomable» valorizado en los escritos sobre las rebeliones indígenas del siglo XVIII: ¿existiría sin embargo el riesgo de que esta celebración de El Alto no produjera sino una simple inversión de las categorías coloniales?

El Alto es una ficción política fruto de la importancia simbólica de la ciudad en la política boliviana que refleja toda una labor de reconstrucción de la historia contemporánea del país. Ficción política que sigue alimentando los fantasmas de los sectores urbanos acomodados de La Paz con respecto a la «peligrosidad» de El Alto y sus habitantes, así como los fantasmas de los militantes políticos que han abandonado la «lucha de clases» por la «rehabilitación de las identidades indígenas campesinas originarias» valorizadas por la nueva Constitución política del Estado, votada en 2009 bajo el gobierno del presidente Evo Morales. La visión de El Alto como «ciudad aymara», poblada por migrantes de las zonas rurales, permite recuperar ese legado político sin mucho esfuerzo, ocultando los problemas que plantean la economía informal, la negación constante de todos los derechos laborales y la violencia de las relaciones sociales internas. En ninguna parte se expresa mejor este imaginario que en el siguiente pasaje de un libro publicado por una organización cultural local con el título De pueblo vacío a pueblo grande. Pequeñas historias contadas desde el alma misma de El Alto:

«El Alto no es una ciudad cualquiera, es el territorio construido por obra de sus propios habitantes. En este lugar, el vecino tiene el orgullo de gritar y contar sus vivencias pues nadie como ellos tuvieron la dicha de construir su ciudad a su estilo, a su manera, a su gusto y con sus propias contradicciones (Quispe Villca, 2004)».

En esta cita se encuentra condensado el imaginario comúnmente difundido acerca de la ciudad:

- en primer lugar, una ciudad que se habría hecho sola, cuando en realidad es el efecto de procesos que vienen afectando a los espacios rurales y urbanos circundantes desde hace más de un siglo (desarrollo de los transportes, migración rural, cierre de las minas, congestionamiento urbano en La Paz, especulación inmobiliaria, etc.);

2 Para un análisis histórico, ver Dunkerkey, 1984.

3 El 6 de agosto de 2009, Evo Morales dijo en la conmemoración de los 24 años de la fundación de la ciudad de El Alto: «Quiero expresar mi máximo respeto y admiración hacia esta ciudad de El Alto, pueblo rebelde, pueblo valiente, pueblo que lucha por la liberación y contra la opresión; pueblo de ejemplo y símbolo en la defensa del Estado boliviano». Ver Alvizuri, 2009. 
- en segundo lugar, una ciudad cuyos habitantes se politizan (y se rebelan) espontáneamente, por el mismo hecho de residir en ella4, cuando en realidad forman parte de juntas vecinales, de elevada densidad organizacional, que se han ido constituyendo paulatinamente a raíz de las dificultades para acceder a los servicios urbanos básicos y, por ende, solo los sectores más estructurados de la ciudad se movilizaron en los años 2000;

- en tercer lugar, una esencialización de la ciudad y su población, supuestamente dotada de características únicas (estilo, manera, gusto) y hasta «contradicciones» que permiten decir cualquier cosa.

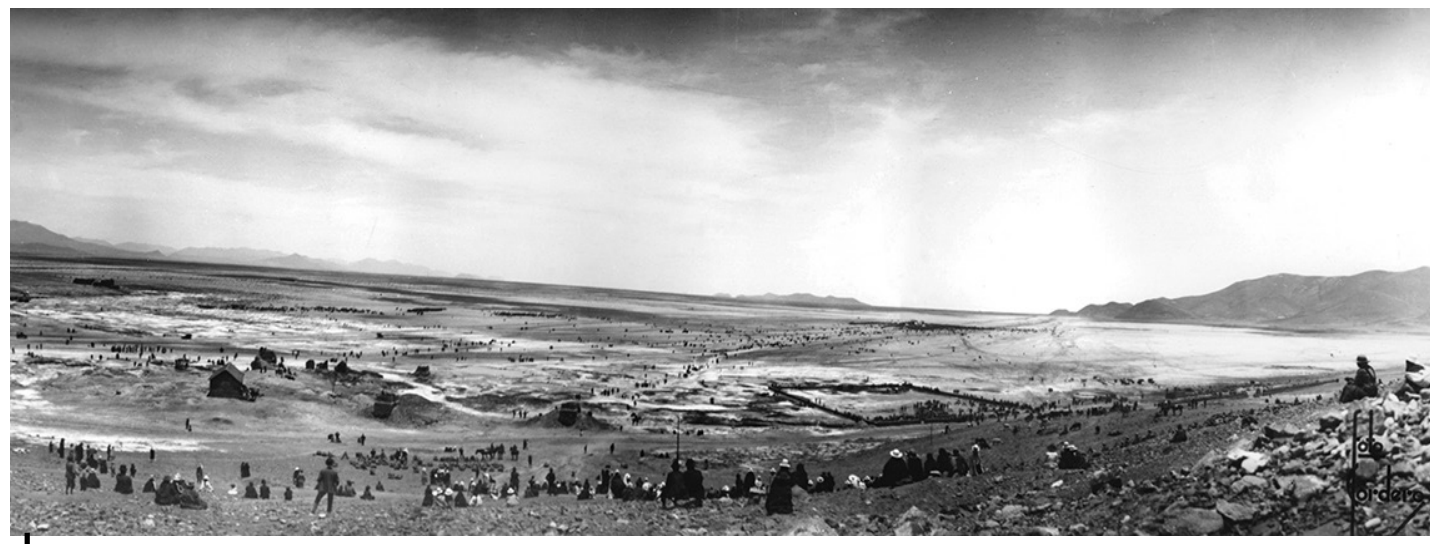

Figura 1 - El Alto a principios del siglo XX: ¿un espacio vacío?

Foto: J. Cordero

Tampoco se trata, sin embargo, de ocultar la significación política de las insurrecciones contemporáneas y de las demandas de reapropiación de los recursos naturales (el gas en 2003 y el agua en 2004-2005). Otro peligro sería caer en una crítica fácil de la imaginería militante y de las visiones «indígenas» - en el sentido de visiones construidas a nivel local por los habitantes mismos o por sus portavoces- En efecto, la ficción política de El Alto forma parte de la definición de la ciudad y de la identidad sociocultural de su población. Más concretamente, el hecho de que El Alto se haya construido y siga construyéndose en la autocelebración de sus propias capacidades de autonomía y movilización, frente al reflejo despectivo que se le envía, en particular desde La Paz, forman parte de la realidad a analizar. Por otra parte, las luchas están en el centro de la representación de El Alto y ésta es tanto más sensible cuanto el proceso de transformación social en curso descanse sobre una representación idealizada de las comunidades «indígenas originarias campesinas»; y que la oposición al gobierno insiste en que la hegemonía de esta visión va en detrimento de los otros grupos que componen la sociedad boliviana. Es precisamente por esta razón

4 El eslogan «El Alto de pie, nunca de rodillas» fue el símbolo de la «guerra del gas» de octubre de 2003. 
que no es posible tomar al pie de la letra esa imagen de la «ciudad aymara» en lucha permanente: al contrario, el proceso de objetivación sociológica la debe considerar como una representación social y políticamente construida, para poder dar cuenta de la «politización de la etnicidad» que se ha producido en la historia reciente de las movilizaciones de esta ciudad (Hylton \& Thompson, 2007). Para ello, hay que ver hasta qué punto El Alto constituye una ilustración del proceso que Marshall Sahlins denominó «la indigenización de la modernidad» (2007)5: la capacidad de resistencia de los pueblos indígenas (de los diferentes continentes) a la modernidad capitalista y a la hegemonía occidental, mediante la apropiación de los bienes y de los símbolos colonizadores, para luego reutilizarlos con una nueva finalidad. La hipótesis de este artículo es que El Alto representa sobre todo la encarnación de una relación moderna con las culturas tradicionales donde coexisten el conservatismo social con transformaciones culturales, la reproducción de las desigualdades y la invención de nuevas formas de expresión. Esta mezcla de relaciones socioculturales permite cuestionar a la vez el comunitarismo y la visión folclórica (o el comunitarismo folclórico) de los pueblos andinos (Galinier \& Molinié, 2006), convertidos hoy en día en ideología de Estado y tendientes a sustituir la lucha contra las desigualdades sociales por una política de identidades.

\section{NACIMIENTO DE UNA CIUDAD PERIFÉRICA}

El Alto es el resultado de una segregación socio espacial que se remonta al siglo XVI, cuando se fundó la ciudad de Nuestra Señora de La Paz, de la cual no fue más que un apéndice durante largo tiempo (Medinacelli, 2009; Cajías et al., 2007). Esta se reducía en unas calles en damero, separado de los barrios indígenas por un río, el Choqueyapu, que atravezaba el valle y en el cual desembocaban

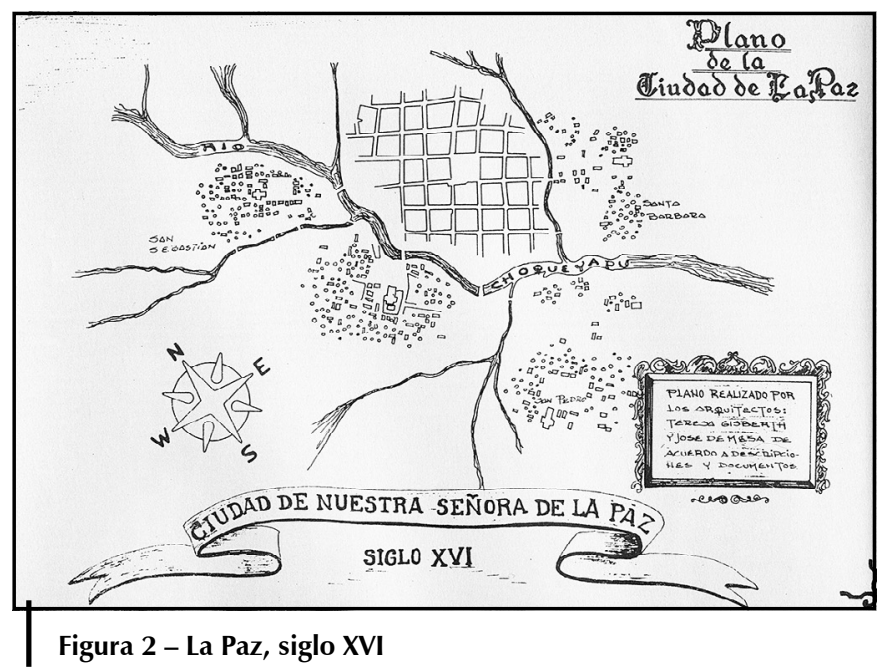

5 Sobre la relacion entre etnicidad y clase, ver Agier, 1992. 
la mayor parte de los cursos de agua que surcaban la hoyada, antiguamente poblada por diferentes grupos étnicos. Se trataba por lo tanto de tierras fértiles y esta fue la razón principal de la fundación de la ciudad de La Paz en este lugar en el siglo XVI, siendo la otra razón el hecho de que estuviera situada en un sitio estratégico entre el centro minero de Potosí y el centro económico de Cuzco. El valle estaba poblado desde hacía aproximadamente 3000 años y el nombre, «originario» del lugar era Chuquiago (chuqui significa oro y apo/apu, rey, para los incas): era pues un centro de producción de oro que contaba además con la presencia multicultural de poblaciones indígenas aymaras, quechuas y puquinas. A partir de entonces, El Alto abarca un territorio designado como Ch'usa Marka (pueblo vacío), inicialmente ocupado por diferentes comunidades, en el que se crearon parroquias coloniales que lo vincularan a La Paz y que luego se dividió en haciendas con las consiguientes expropiaciones y desplazamientos de poblaciones. De ahí que Juan Manuel Arbona dijera en su estudio sobre la historia de El Alto:

«esta ciudad nació de varios procesos históricos y coyunturas sociales: de la oportunidad (y del oportunismo) que conlleva la apropiación de la tierra y la consolidación de un espacio urbano; de la promesa de la ciudad a una estabilidad económica y mejoramiento de la situación social. En este sentido, no se puede decir que El Alto nació como una ciudad politizada, sino más bien fue politizada a raíz de la marginalización y exclusión en la que han vivido la mayoría de sus residentes, que no han tenido la posibilidad de cobrar en la promesa. Los alteños/as han tenido que construir su ciudad bajo la sombra histórica de una ciudad que pretendía su inexistencia» (Arbona, en prensa).

En los relatos de viajeros, como Alcide d'Orbigny, la extensión y la población de lo que se convertirá en El Alto, son ignoradas: el espacio vacío del altiplano contrasta demasiado sin duda con la majestad de las montañas al pie de las cuales se acurruca el espacio urbano paceño (Miller, 2007).

La expulsión de las poblaciones indígenas comienza en el siglo XVIII con la complicidad de algunos caciques que permiten que los españoles y los criollos de La Paz se apropien de las tierras (Barragán, 1990; Saignes, 1992; Albó, 1999; Escobari, 2005). La agrupación de los indios en las reducciones había empezado en el sigo XVI con el fin de facilitar la explotación de la mano de obra. Sin embargo, el siglo XVIII marcó verdaderamente la decadencia de la organización en ayllus: la creciente escasez de tierras obligó a las poblaciones indígenas a mirar hacia La Paz y a dedicarse a actividades no agrícolas y subalternas como las de empleados domésticos, jornaleros en las haciendas, pequeños artesanos y pequeños comerciantes de productos de primera necesidad, etc. Los barrios indios en expansión constituyeron zonas:

«donde se comerciaba, donde se prestaban servicios y donde se acudía por la mano de obra necesaria para la propia expansión y construcción de la ciudad (Barragán, 1990: 22)».

La integración a la ciudad se hizo bajo el signo de la desigualdad de condiciones de vida y de estatutos. Mientras La Paz se desarrollaba poco a poco por todo 
el espacio disponible de la hoyada, los territorios que se convertirían en El Alto pero, que en ese momento, formaban parte de las parroquias de San Pedro y San Sebastián, se desarrollaban, a lo largo del siglo XIX, en una planicie situada en lo alto, expulsando a los comunarios y creando haciendas alrededor de La Paz (Rivera, 1978).

Una perspectiva histórica permite aportar algunas precisiones sobre la ubicación real de los ayllus que han ido desapareciendo poco a poco:

«de manera preliminar, y deduciendo de los padrones e inscripciones de $1770,1786,1852, y 1881$, se puede estimar que los ayllus que conformaban El Alto contemporáneo eran: Cupilupaca, Checalupaca, Chinchalla y Pucarani. Esta deducción surge a partir de los nombres de las estancias que pertenecieron a los ayllus, y otros detalles en las narrativas de los padrones coloniales. [...] Algunas zonas mantuvieron los nombres de estas estancias y haciendas. [...] Por otro lado, en los padrones revisados hay referencia a que estas estancias estaban en "la altiplanicie", además de las menciones de los linderos, por lo que sugiere que estaban en las inmediaciones de El Alto. Similarmente, contrastando los padrones de 1852 y 1881, y analizando los linderos que menciona el padrón de 1881, se puede deducir dónde estaban y cómo se llamaban las haciendas localizadas en El Alto contemporáneo. [...] Para el Catastro de 1919 estas haciendas seguían vigentes (excepto 2), aunque la mayoría con diferentes propietarios. Todas estas haciendas eran principalmente de producción agrícola y ganadera, aunque algunas también se dedicaban a la minería en pequeña escala. Comparando el valor de estas haciendas con otras de las Parroquias de La Paz, se puede constatar que estas eran de menor valor posiblemente debido al limitado acceso a recursos hídricos (Arbona, en prensa)».

La expansión urbana no se hizo sin conflictos: pese a que la Ley de Ex Vinculación de 1874 declaró «extinguidas las comunidades» y ordenó «la dotación individual de parcelas a los indígenas comunarios», como consecuencia de lo cual las tierras comunitarias se convirtieron en haciendas y los campesinos en mano de obra barata, los habitantes trataron de oponerse a ello presentando títulos colectivos de propiedad fechados de los siglos XVI y XVII (Rivera, 1978). Se encuentra incluso la manera de utilizar sentencias de esa época en los conflictos de tierras de los años 1960 y 1970; en 1983, sobre esa base, obtuvieron la promulgación de una ley que permite derogar la de 1874 .

Por lo tanto, hasta principios del siglo XX, el espacio estuvo ocupado principalmente por grandes propiedades que compartían las tierras con algunas comunidades campesinas, empresas privadas e instituciones públicas. En 1912, en el lugar del sitio actual de La Ceja (el punto de conexión de la autopista actual entre La Paz y El Alto), se creó una estación ferroviaria de propiedad del Ferrocarril Guaqui-La Paz, donde se instalaron también oficinas y depósitos. En 1923, la fundación de la escuela de aviación, precedió la implantación de las oficinas de la compañía aérea Lloyd Aéreo Boliviano, alrededor de un pequeño aeródromo. Diez años más tarde, a su turno, la empresa nacional YPFB instaló sus depósitos. La urbanización empezó 

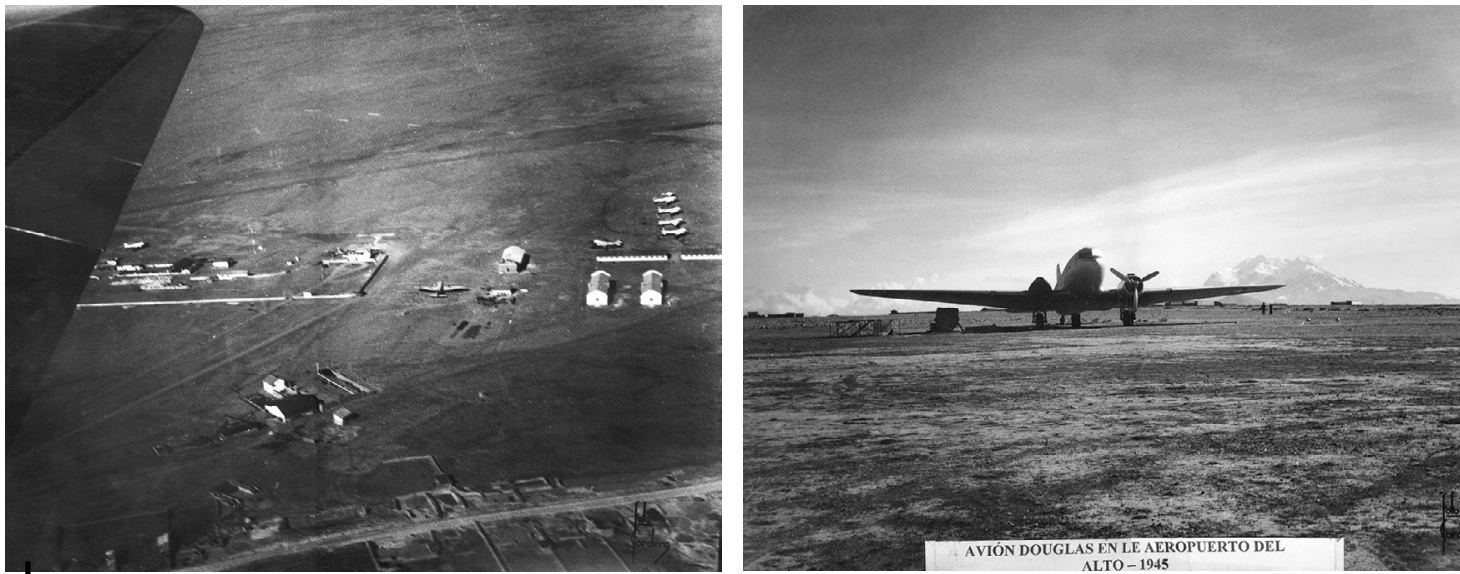

Figuras 3 y 4 - El terreno de aviación en los años 1940

Fotos: J. Cordero

verdaderamente en los años 1940, impulsada por las haciendas que vendieron los espacios en los que se ubicarían los diferentes barrios, transfiriendo 134000 títulos de propiedad (Demoraes, 1998): en 1942, se fundó Villa Dolores (que se convertirá en Ciudad Satélite) y hasta la Revolución Nacional de 1952 nacieron los barrios de Bolívar y 12 de octubre en el sur, 16 de Julio, Ballivián y Alto Lima en el norte. La expropiación de la hacienda El Tejar, en el momento de la Revolución, liberó toda la zona de La Ceja y permitió la fundación de Ciudad Satélite:

«sus principales pobladores fueron personas que se dedicaron al pequeño comercio (venta de frutas y comida en la inmediaciones de La Ceja). Las otras áreas, como Villa Dolores, sólo contaban con algunas pequeñas edificaciones muy precarias; fueron ocupadas por los flujos migratorios provenientes de provincias y por pobladores urbanos, que por motivos económicos no pudieron asentarse en la ciudad de La Paz y aprovecharon del precio muy bajo de la tierra (Garfias \& Mazurek, 2005: 11)».

En una primera fase, El Alto se desarrolló en torno a los ejes camineros, a lo largo de los cuales se implantaron las viviendas. Las carreteras que unían El Alto con otros centros urbanos del altiplano (Oruro, Copacabana, Laja, Viacha) convergían en el cruce de La Ceja. Los barrios más antiguos contaron con servicios urbanos (agua y electricidad) desde los años 1950. A partir de aquel entonces, el crecimiento de la población fue espectacular: 11000 habitantes en 1950, 30000 en 1960, cerca de 100000 en 1976, 405500 en 1992 y 647000 en 2001. Semejante crecimiento (superior al $9 \%$ anual entre 1976 y 1992) se explica en primer lugar por las primeras olas de migración rural que, a partir de los años 1970, resultaron de la crisis del sistema rural de economía familiar (puesto que las parcelas delimitadas por la reforma agraria de 1953 eran demasiado pequeñas para ser distribuidas entre todos los herederos de la generación siguiente). La sequía, debida al fenómeno de El Niño provocó un segundo éxodo a principios de los años 1980. Por último, a partir de 1985, la crisis en los mercados de materias primas, así 
como las primeras medidas de liberalización de la economía provocaron el cierre de numerosos centros mineros y la migración masiva de mineros procedentes de los departamentos de Potosí, Oruro e incluso La Paz (otra corriente importante de migración se dirige al departamento de Cochabamba y más precisamente al Chapare, fortaleciendo los sindicatos de cocaleros).

En los archivos municipales se encuentran rastros de las juntas vecinales desde 1957, movilizadas principalmente para obtener acceso a los servicios urbanos básicos: saneamiento, agua y electricidad. Asimismo en el libro La ciudad prometida de Sandoval \& Sostres (1989: 22) se hace referencia a «comandos zonales» que el MNR organizó apenas llegó al poder: impulsaron la creación de «sindicatos de inquilinos» de los que nacieron las juntas vecinales y cuyos miembros fueron los primeros beneficiarios de la política oficial de entrega de lotes: en particular, entre 1957 y 1959, se otorgaron lotes en Ciudad Satélite, las villas Santa Rosa y Rosas Pampa a funcionarios de la policía. En los doce años de gobierno del MNR no se adoptaron políticas específicas a favor de esas zonas, sino medidas locales y limitadas, a menudo bajo presión de los habitantes (especialmente creación de mercados y de escuelas primarias). Sin embargo, el proceso de la Revolución Nacional dio inicio a «la incorporación de El Alto como apéndice de la ciudad de La Paz (Sandoval \& Sostres (1989: 23)».

En efecto, la Revolución de 1952 propició procesos de mediación entre el pueblo y el Estado, tanto en el caso de reivindicaciones materiales como en el de participación popular. Este proceso se desarrolló bajo el signo del «clientelismo burocrático»: controladas por los militantes del MNR, las primeras juntas vecinales respondieron en realidad a la voluntad de organizar políticamente a los sectores populares. Bajo los gobiernos autoritarios de los años 1960 y 1970, las relaciones con el Estado se caracterizaron por una sumisión ideológica relativamente fuerte, pero la crisis económica alimentó poco a poco las protestas: en 1978, las juntas vecinales participaron activamente en los movimientos que reivindicaban un régimen democrático y se oponían a los golpes de estado de Natush Bush (1979) y García Mesa (1980). Sin duda no es por casualidad que la Federación de Juntas Vecinales (Fejuve) se creó oficialmente en esa época, en 1979. Un congreso que reunió a las juntas vecinales definió la federación como una organización encargada a la vez de representar a la población de las zonas de El Alto en lo referente a los servicios y a las infraestructuras a nivel local y de servir de lazo con las reivindicaciones democráticas a nivel nacional. El regreso a la democracia en 1982 gracias a la Unidad Democrática y Popular marcó una nueva etapa en el desarrollo de las juntas vecinales: una relación ambivalente de negociación y de oposición al Estado que asistió a la interpelación de las autoridades por las organizaciones cívicas que reclamaban mejores condiciones de vida luego de una quincena de años de ausencia de políticas públicas para sus barrios. El Alto dejó de ser un barrio de La Paz en 1985, como consecuencia de una lucha que duró varias décadas6.

El Consejo Central de Vecinos, creado en 1957, había iniciado la demanda de autonomía administrativa pero recién en 1983 tuvo lugar un encuentro entre el

6 Se había dotado a El Alto de una alcaldía anexa a principios de los años 1980. 
consejo municipal de La Paz y los representantes de las juntas vecinales de la Fejuve: el proyecto del diputado Antonio Araníbar contemplaba, entre otras cosas, una capacidad de gestión autónoma de los recursos económicos, administrativos y técnicos (Sandoval \& Sostres, 1989: 23). El encuentro no desembocó en nada en lo inmediato y el 6 de marzo de 1985, otra organización cívica, llamada Frente de Unidad y Renovación independiente de El Alto (Furia) conformada por ex dirigentes de la Fejuve, logró que el Congreso reconociera la autonomía administrativa mediante la creación de la cuarta sección de la provincia Murillo con El Alto por capital. Exactamente tres años más tarde, bajo la presión de las organizaciones cívicas y comerciales, El Alto fue reconocido por el Congreso como una verdadera ciudad (la aprobación definitiva tuvo lugar el 12 de septiembre del mismo año)7.

\section{ESPACIO URBANO Y ESPACIO SOCIAL: LA ESTRUCTURA DE LAS DESIGUALDADES}

La población activa de El Alto que, según el censo de 2001, comprende a unas 230000 personas, está integrada en su mayoría por obreros (47 \%) y por empleados y trabajadores independientes (41\%). El comercio mayorista y minorista representa un $30 \%$ de las actividades, mientras que la industria, el transporte y la construcción ocupan al $23 \%$, 10 \% y $8 \%$ de la fuerza laboral, respectivamente. El sector secundario está dominado por la construcción que agrupa la tercera parte de los empleos del sector secundario y representa el $10 \%$ de la fuerza laboral alteña. Como lo nota Virginie Baby:

«siempre hay obras, puesto que la ciudad está en permanente crecimiento, pero ese sector es relativamente inestable, pues los ingresos de los trabajadores dependen de las obras que los emplean y de las necesidades de éstas» (Baby, 1995: 142).

Desde el punto de vista espacial, las actividades comerciales y los servicios están muy concentrados en el sector de La Ceja, mientras que las grandes industrias se encuentran sobre todo en los barrios periféricos (norte de Alto Lima, zona franca en el camino a Oruro). El sector terciario consiste sobre todo en pequeños negocios tradicionales (18 \% de las actividades), atendidos por mujeres, en empleos domésticos, y unos pocos cuadros superiores. Si bien El Alto alberga a más industrias y actividades artesanales que La Paz, sobre todo por la mayor disponibilidad de espacios baratos para su instalación, su relación con la capital

7 El hecho que se hable de las juntas vecinales de los barrios no debe ocultar ni la multiplicidad ni la diversidad de las organizaciones sociales, sindicales y culturales de El Alto: federación de los comités de padre de familia, clubs de mujeres, asociaciones de mineros relocalizados, centros culturales para los jóvenes o los residentes de un barrio, la Central Obrera Departamental, etc. Todos estos grupos tejen las relaciones sociales entre los habitantes de una misma zona, conectándolas a nivel municipal. Constituyen a la vez redes de ayuda mutua y de control social de los dirigentes destinadas a paliar la ausencia del Estado, ilustrada por el siguiente dato: solo hay 2000 policías en todo El Alto y esto siempre que no se los traslade al centro de la ciudad para vigilar partidos de fútbol. 
del departamento es de verdadera dependencia, ya que entre 100000 y 200000 personas bajan diariamente a La Paz para trabajar.

Al final, no se debe caer en una visión homogénea e indiferenciada de la ciudad, pues «El Alto no es un suburbio miserable», como lo demuestran Marie-Danièle Demélas y Jean-Pierre Lavaud, basándose en los datos siguientes: El Alto es la segunda ciudad industrial del país, con más de 5000 establecimientos8, los cuales habrían generado 270 millones de dólares en productos manufacturados, exportados principalmente a Estados Unidos —en primer lugar, la industria de la confección, seguida por las fábricas de muebles, la industria mecánica, la producción de alimentos y la producción textil y, en segundo lugar, las industrias de la madera, de los plásticos, la industria gráfica, etc.- - Aunque «los conflictos sociales acompañados de bloqueos de caminos y frecuentes manifestaciones han desanimado a algunos empresarios», el hecho de que se creen anualmente más de 1000 empresas es una «prueba del dinamismo de la ciudad» (Demélas \& Lavaud, s.f.) Dinamismo que los datos del Instituto Nacional de Estadística (INE) confirman en 2008: ese año, la población activa llegó a las 500000 personas, aproximadamente, es decir prácticamente el doble de lo que era en los años 2000; 19098 empresas están registradas como contribuyentes en el Servicio Nacional de Impuestos, pero con los regímenes especiales, las recaudaciones fiscales apenas sobrepasan los 60 millones de Bolivianos. Si bien El Alto no es una villa miseria, es una ciudad segregada en la que impera la desigualdad y la informalidad vinculadas con una estructura corporatista (ver recuadro 1).

\section{Recuadro 1 - Desempleo y trabajo informal en El Alto}

Según el censo de 2001, más del 90 \% de la población activa gana menos de 2600 Bolivianos mensuales, lo que significa que el 49,3 \% de la población está en situación de «pobreza moderada» y el 25,6 \% en situación de gran pobreza, mientras que solamente el 7,5\% tiene todas las necesidades básicas satisfechas (vivienda, alimentación, empleo). El desempleo, que en 2008 afecta al $13 \%$ de la población activa, es el principal problema de la ciudad, según el sociólogo Carlos Hugo Laruta9. La estimación del desempleo, que afecta sobre todo a los jóvenes, se ve seguramente atenuada por el hecho de que en El Alto predomina sobre todo el sector informal, en el que trabajaba el $75 \%$ de la población activa de la ciudad en 1996 y el $70 \%$ en 2006, tasa muy superior a las de otras ciudades grandes del país (en que el trabajo informal se sitúa entre el $50 \%$ y el $56 \%$ ) (Yanez \& Landa, 2007). De manera más general, los trabajadores del sector informal, es decir el $63 \%$ de la población activa boliviana en 1996 y el $58 \%$ en 2006, son en su mayoría mujeres (respectivamente el $68,1 \%$ y el $62,7 \%$, frente al $58,8 \%$ y el $54,4 \%$ de los hombres), indígenas (respectivamente el $71,3 \%$ y $69,2 \%$, frente al $58,2 \%$ y el 49,2 $\%$ de los no indígenas) y pertenecen a dos categorías de edad específicas, menores de 25 años y mayores de 44 años (en proporciones siempre superiores al $50 \%$ ).

8 De los cuales el 90,6 \% son microempresas que emplean de una a cuatro personas, lo cual representa el 45 \% de los empleos: ver Cámara Departamental de Industrias de La Paz, 2004.

9 El autor se presenta como «sociólogo alteño» y fue director del CIPCA-La Paz (Centro de Investigación y Promoción del Campesinado). http://www.iglesiaviva.net/content/view/2998/80 
El empleo informal caracteriza sobre todo las pequeñas entidades semiempresariales (con menos de cuatro empleados) y las empresas familiares (trabajo por cuenta propia o trabajo en la casa no remunerado), que constituyen, como se vio anteriormente, la gran mayoría de los establecimientos económicos de la ciudad. La relación entre esta estructura económica y el voto masivo, en los años 2000, por el Movimiento Al Socialismo de Evo Morales en El Alto, demuestra que este partido no solo es una federación de organizaciones sociales, sino también la expresión política de los pequeños productores nacionales (Do Alto, 2009): esta base corporativa del MAS contradice la visión esencialista y culturalista de «El Alto de pie», especialmente si se considera que el corporativismo alteño se acompaña de tomas de posición que pueden difícilmente ser presentadas como «revolucionarias» (especialmente sobre el aborto o los derechos de trabajo). En este sentido, el MAS recupera en El Alto el voto del partido populista Condepa que había transformado el campo político local de los años 1990, y que constituía un rechazo de la política «tradicional» de los partidos políticos dominantes (Alenda, 1999).

El Alto es una ciudad sumamente compartimentada: es común que las tiendas y los talleres de un mismo oficio se sitúen en una misma calle, por ejemplo, los trajes de fiesta y de ceremonia en la 16 de Julio o las calles de chatarreros, carpinteros o mecánicos. Esta organización corporativa, que se repite también en la feria bisemanal de la 16 de Julio, más allá de su aparente abundancia, es solo el aspecto más visible de la inscripción de las jerarquías del espacio social en la materialidad del espacio urbano. Detrás del mosaico de los barrios y la aparente urbanización descontrolada, existe, al menos en las partes más antiguas y centrales de la ciudad, todo un orden corporatista que estructura el espacio. A fines de los años 1980, Sandoval y Sostres describían una ciudad compuesta por tres conjuntos distintos (Sandoval \& Sostres, 1989: 31-36)10. La zona central, en torno a La Ceja, Ciudad Satélite y las villas Bolívar, 12 de Octubre y Dolores, albergaba a habitantes de clase media procedentes del altiplano y a empleados de las administraciones locales; era la mejor dotada de equipamientos urbanos e incorporaba también a migrantes rurales de condición modesta, una de cuyas modalidades de inmigración consistía en empezar por irse a vivir a la casa de familiares instalados en la ciudad (Albó et al., 1981-1986). La zona sur, la más reciente y la que menos acceso tenía a los servicios urbanos, albergaba a lo largo del camino a Oruro a migrantes procedentes de las zonas mineras del altiplano y a empleados de bajos ingresos. La zona norte, más arriba del camino a Copacabana, era en cambio el lugar de acogida de los campesinos aymaras del departamento de La Paz. Como tal, era verdaderamente heterogénea, pues albergaba a trabajadores precarios que habían abandonado el mundo rural por falta de tierras y la burguesía urbana aymara, comerciante y artesanal (como la de la calle Buenos Aires de La Paz). La descripción de Sandoval y Sostres sigue siendo globalmente válida, siempre que se tengan en cuenta la expansión urbana y las transformaciones cualitativas del proceso de poblamiento

10 Los autores se basan sobre todo en el estudio del geógrafo alemán G. Koester, 1976. 
y de los modos de asentamiento en El Alto, en particular en las zonas periféricas: la cartografía de los datos del censo 2001 permite distinguir entonces tres anillos distintos (ver recuadro 2 ).

\section{Recuadro 2 - Los tres anillos de El Alto}

El análisis cartográfico de los datos del censo de 2001 por Garfias \& Mazurek (2005) muestra que El Alto está ahora compuesto por tres círculos espaciales distintos, correspondientes a la antigüedad de la implantación de los diferentes barrios y a la centrífuga dinámica urbana. Se elaboraron varios indicadores, teniendo en cuenta la calidad de las viviendas (paredes de ladrillo o de adobe, suelo de cemento o tierra, número de habitaciones, etc.), su acceso a los servicios urbanos, las características sociodemográficas de los jefes de familia (profesión, sector en el que trabajan), la dependencia de la familia de la persona activa, el acceso a los servicios de salud (con el número de partos a domicilio). El primer círculo está constituido por La Ceja y los primeros barrios construidos en los años 1950 (Villa Dolores, Ciudad Satélite, 16 de Julio, Ballivián). Se caracteriza por una elevada densidad demográfica, viviendas construidas con materiales modernos y con buen acceso a los servicios básicos, un elevado porcentaje de la población activa empleada principalmente en el sector del comercio y los servicios, que coexiste con pequeños empresarios independientes y personas que trabajan en su casa: todas estas características del empleo explican la baja tasa de analfabetismo y la gran proporción de mujeres.

El segundo anillo se caracteriza por situaciones de lo más variadas, pues corresponde al asentamiento en los años 1970-1990: migración rural debida al clima (fenómeno de El Niño) y la crisis de reproducción del pequeño campesinado del altiplano, enfrentada a parcelas demasiado estrechas, heredadas de la distribución de la revolución de 1952, cierre de las minas debido a la crisis en los mercados mundiales y a las reestructuraciones liberales de 1985 y crecimiento endógeno de la población alteña. Se puede distinguir al norte del aeropuerto una población que trabaja por cuenta propia o empleada a domicilio y al sur una población de obreros y empleados a la vez más estable y más calificada, pero al parecer con viviendas todavía relativamente precarias. El tercer anillo está compuesto por las urbanizaciones más recientes, que datan de la segunda mitad de los años 1990, agrupadas en los distritos 7 y 8, así como en el norte de los distritos 5 y 6 y al oeste de los distritos 3 y 4 . Este círculo presenta las superficies más grandes y también los niveles de densidad de viviendas más bajos, lo cual dificulta su acceso a los servicios básicos. Al norte del aeropuerto se encuentra, al igual que en el segundo anillo, una población poco calificada y más joven que en el resto de la ciudad11. La estructuración socio espacial a la que obedecen la mayoría de las variables y que lleva a interpretar el espacio urbano alteño en términos de segregación, presenta un interés científico particular: los indicadores de ubicación espacial son, al menos, igual de predictivos que los indicadores sociales tradicionales. El análisis cartográfico resulta ser pues un complemento indispensable de la encuesta sociológica, cuando los datos sobre la profesión o la clase social, en un contexto muy segregado, no aportan suficiente información sobre los individuos o los grupos encuestados (Poupeau, 2008).

11 En la ciudad en su conjunto, la edad media es de 22,6 años, según el censo de 2001. Los menores de 15 años representan el 39,5 \% de la población, pero se concentran sobre todo en el segundo anillo, mientras que la mayor parte de los centros educativos y culturales se sitúan en el primer anillo. 


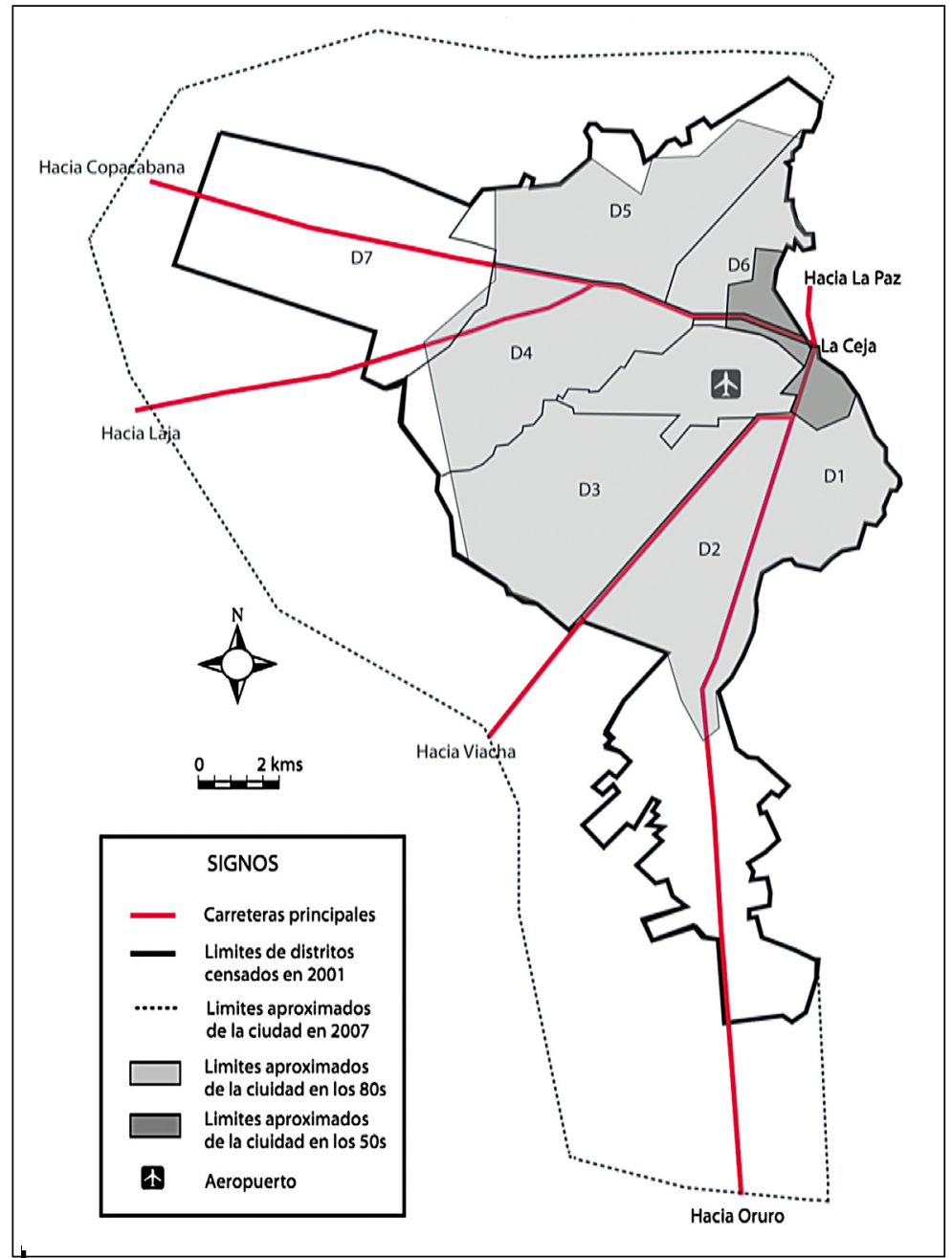

Figura 5 - Mapa de El Alto y representacion esquematizada de sus anillos

Realización: Franck Poupeau

En cambio, la encuesta realizada por el equipo del Instituto Francés de Estudios Andinos (IFEA) en 2007 (Poupeau, 2010), aunque confirma los elementos esenciales de los análisis cartográficos anteriores, lleva a conclusiones diferentes en lo referente a los modos recientes de instalación, en particular en lo relativo al tercer anillo, que correspondería «a zonas de recepción de una población de migrantes, en general jóvenes y casados» (Garfias \& Mazurek, 2005: 102). Ahora bien, ciertos indicadores muestran que, a parte de ciertas zonas del distrito 7 (al oeste del camino a Copacabana), en las que aún se registra el asentamiento evidente de población de origen rural, ese tercer anillo se caracteriza por tasas de familias propietarias de su vivienda más altas que en el resto de la ciudad, 


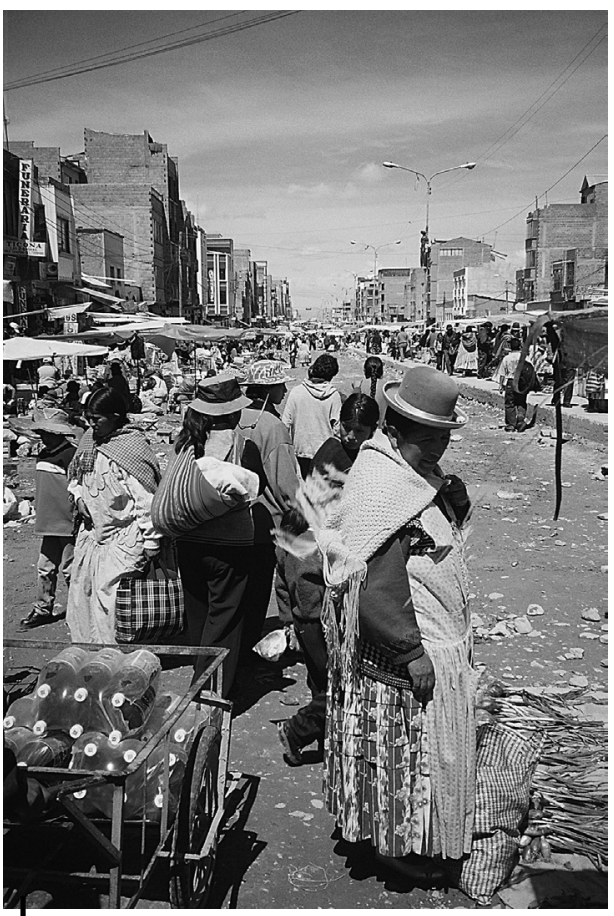

Figura 6 - Un mercado alteño

Foto: Franck Poupeau lo cual cambia el sentido que se le puede dar a la población de migrantes «jóvenes y casados». Los cuestionarios difundidos en esas zonas por el equipo del IFEA revelan que se trata más bien de una migración intraurbana, mediante la cual parejas jóvenes (de 30 a 40 años principalmente) acceden a la propiedad: en la mayoría de los casos en asentamientos salvajes y no planificados por la municipalidad, en los que la autoconstrucción de viviendas de adobe coexiste con la especulación inmobiliaria por pequeños propietarios que compran lotes para revenderlos a ese tipo de familias, a precios más altos pero siempre menores a los de las viviendas más céntricas. Las familias con varios hijos están pues dispuestas a sacrificar cierto nivel de comodidad (en promedio hay que esperar dos años para tener electricidad y cinco años para poder conectarse a la red de agua potable) con tal de adquirir una vivienda propia, con más espacio para los hijos y sin las limitaciones que supone depender de un dueño de casa exigente.

Por consiguiente, ya no se puede decir que El Alto sea solamente una ciudad de migrantes rurales, habida cuenta del desarrollo endógeno de la ciudad y de las transformaciones cualitativas de los asentamientos de las zonas periféricas. En lo que a los modos de identificación de los habitantes se refiere, la encuesta del IFEA revela que, en esas zonas periféricas en expansión, menos del $30 \%$ de los jefes de familia encuestados se definen como miembros de un pueblo originario: se definen mayoritariamente según un criterio territorial, como alteños (residentes de El Alto). Tanto las autoridades municipales como los proveedores de servicios, públicos o privados, deberían revisar muchos de los estereotipos sobre El Alto, «ciudad de campesinos indígenas»: la población que reside ahora en esas zonas se caracteriza por tener aspiraciones urbanas en lo que respecta al equipamiento, al acceso a los servicios básicos y a las prácticas culturales. Por lo demás, este último aspecto es el más difícil de interpretar: la movilización de los vecinos no se puede reducir a una «politización de la etnicidad» o a un «renacimiento» de la «cultura aymara» en la ciudad, sino tiene que tomar en cuenta esta dimensión «territorializada» de las formas de autoidentificación, y entonces los efectos de las estructuras económicas y sociales. 

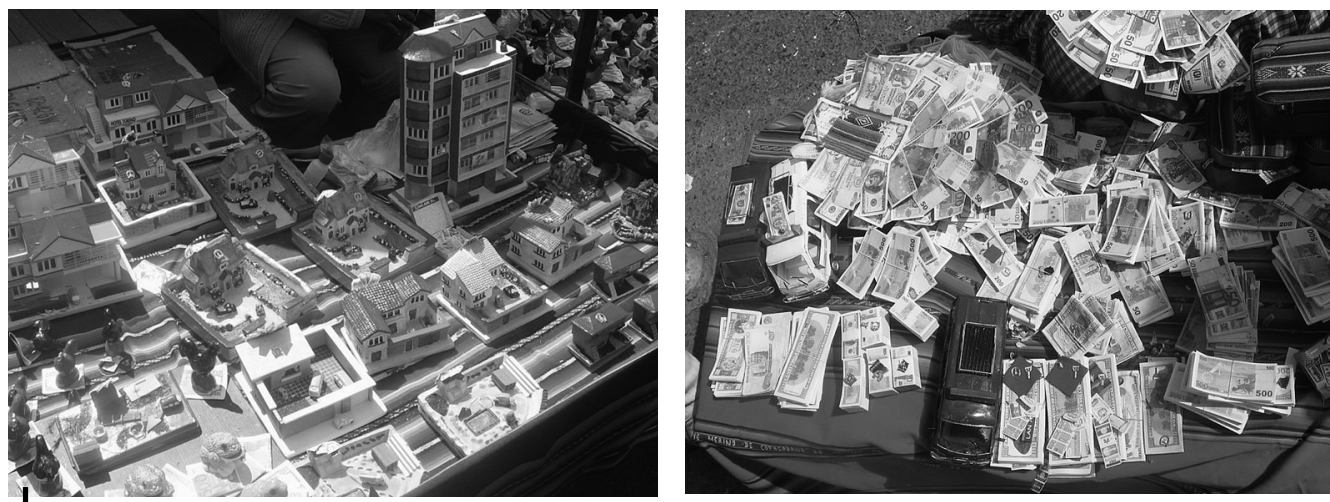

Figuras 7 y 8 - En la fiesta de Alasitas, en enero de cada año, se venden miniaturas de los objetos más necesitados y más deseados

Fotos: Sara Botton

\section{EL ALTO: ¿ UNA INDIGENIZACIÓN DE LA MODERNIDAD O UNA RELACIÓN MODERNA CON LAS TRADICIONES?}

Del análisis socio espacial, se puede concluir que la representación de El Alto como «ciudad aymara» en la que las tradiciones indígenas perdurarían, resistiendo al desarrollo capitalista y a la modernidad occidental, se debe matizar en varios aspectos. En efecto, ese pulmón económico de Bolivia no puede considerarse hermético a la penetración de la «modernidad occidental», trátese de la introducción de mercancías, de estilos de vida o de formas de expresión cultural. La singularidad de El Alto no puede entenderse como la transposición urbana de una «cultura aymara» que hubiera atravesado el tiempo y las colonizaciones (la inca y luego la española), sino como el resultado de complejos procesos de apropiación, de resistencia y de aceptación de elementos «extraños». Por lo demás, esta formulación no es totalmente correcta y se debe ante todo descartar una dicotomía demasiado esquemática entre cultura «tradicional»y cultura «extranjera occidental». Dicha dicotomía, reavivada por el indigenismo político del momento, no hace sino invertir el valor de las categorías más coloniales: presenta sobre todo las culturas indígenas como tradiciones estables y petrificadas. Disfrazada de fidelidad a un pasado idealizado, no es más que una forma de ideología conservadora. Por el contrario, se debe ver que, lejos de estar pasivamente dominadas por la «modernidad occidental», trátese de la Colonia o del capitalismo neoliberal, dichas culturas, Ilamadas «tradicionales», se han construido desde siempre en una interacción constante con las culturas de sus colonizadores, incas, españoles o más generalmente «occidentales»12.

Esta transformación permanente de la cultura se advierte con particular nitidez en los barrios de migrantes rurales. Un estudio sobre las ciudades peruanas de

12 Entre múltiples referencias, se citará en particular a: Abercrombie, 2006; Bouysse-Cassagne et al., 1987. 
Lima y Arequipa revela que los migrantes procedentes de las regiones andinas se diferencian de los de otras regiones del país al mantener un sentimiento de pertenencia a su lugar de origen que les permite reinventar, en otro contexto, las tradiciones culturales de las comunidades rurales (Paerregaard, 2003): por ejemplo, los campeonatos de fútbol constituyen una oportunidad para reproducir las fiestas rurales, con sus rituales de enfrentamientos y libaciones, dándoles a la vez una forma nueva. Como muestra una encuesta realizada a principios de los años 2000 por jóvenes investigadores bolivianos (Guaygua et al., 2003), en El Alto se observan procesos del mismo tipo, sin duda con una tendencia aún más fuerte de las nuevas generaciones a diferenciarse de las primeras generaciones de migrantes aymaras de los años 1960 y 1970. Estos últimos se veían obligados a emigrar por razones principalmente económicas y reproducían por tanto, adaptándolas, las prácticas culturales y los códigos de sus pueblos de origen. Se observa aún esa influencia en el sistema de padrinazgo y la preparación colectiva de las fiestas de barrio, según el modelo algo idealizado de la reciprocidad andina (ayni), que permite redistribuir las riquezas entre los residentes. (Desde ese punto de vista, se debería estudiar el surgimiento, a partir de los años 1970, de una burguesía chola que, decepcionada por el proyecto de integración ciudadana de la Revolución de 1952 que no consiguió que los indios accedieran a la igualdad política, económica y social, creó para sí un ámbito próspero de negocios y un nuevo universo de referencia entre lo rural y lo urbano, al margen de la política nacional, en la invisibilidad de la muchedumbre de las calles Buenos Aires de La Paz y 16 de julio de El Alto.)

En general, «nuevos espacios llevan a la invención de nuevas ceremonias.[...] El estreno de bienes recién adquiridos, como una casa o un auto, se celebra con un amplio grupo de amigos en una nueva forma de ch'alla» (Guaygua et al., 2003: 291). Cierto es que las generaciones jóvenes utilizan mucho las nuevas técnicas

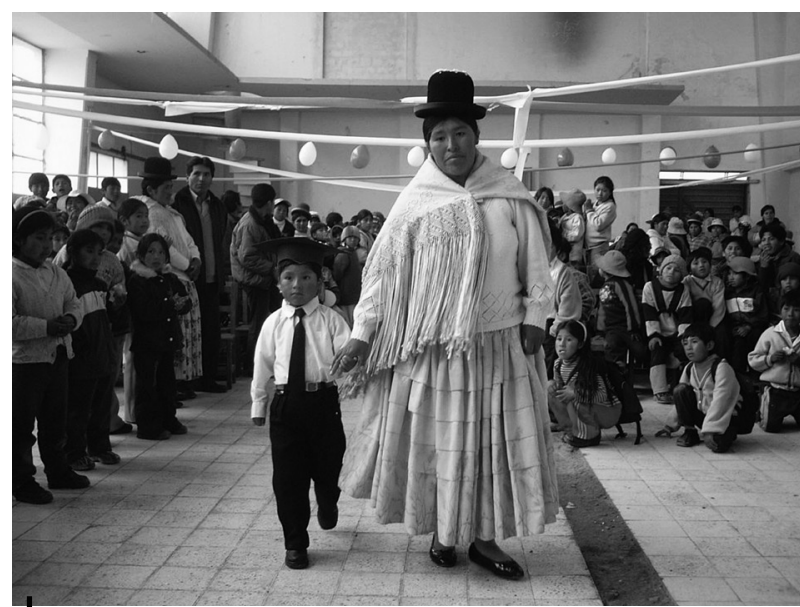

Figura 9 - Un desfile escolar en El Alto, donde se mezclan elementos «nacionales»e «importados» de comunicación e importan modas extranjeras, pero el elemento determinante sigue siendo la influencia del grupo de pares. Así, la importación de música latina (tecnomerengue, cumbia, rock, etc.) pasa menos por la compra de discos que por conciertos de grupos locales, en discotecas («chojcheríos») destinadas a atraer una clientela joven, pero cuya disposición reproduce también la de las fiestas rurales (en particular con sillas alrededor de la pista de baile para ver bailar a unos y otros). El surgimiento de prácticas culturales propias de los jóvenes aymaras en un medio urbano 
no supone entonces la desaparición de los lazos familiares ni una ruptura brutal entre generaciones: tienden a reproducir la cultura de sus padres adaptándola a sus nuevos espacios de socialización o confiriéndole nuevas connotaciones —así pues, los estudiantes dan nuevos colores a danzas tradicionales poco practicadas por los adultos (que a menudo se limitan a bailar «morenada» o «kullawada»)—. Esta renovación de la cultura rural no es para nada incompatible con los blue jeans que reemplazan las polleras de las jóvenes.

La encuesta mencionada sobre los jóvenes aymaras de El Alto, muestra que la confrontación con la «modernidad capitalista» no puede ser asimilada a una entrada pasiva en el universo del consumo ni tampoco a la creación de una «cultura híbrida». Se trata más bien de la reestructuración de elementos culturales urbanos alrededor de elementos de la cultura heredada. Se puede preguntar entonces si sobrevive el campesino en ese nuevo contexto o si, alcontrario, presenciamos la aparición de una nueva cultura aymara en proceso de creación:

«en un medio urbano, los aymaras tienen que hacer frente a contextos que, a primera vista, parecerían incompatibles con sus costumbres tradicionales (Guaygua et al., 2003: 299)».

Sin embargo, los elementos extranjeros son incorporados a través de las culturas juveniles de las cuales surgen una nueva configuración y una transformación de lo aprendido y transmitido en la familia:

«lo específicamente andino no se expresa únicamente en los estilos de vida aymara tradicionales sino que se encuentra tanto en el joven que va a una discoteca vestido a la moda como en el campesino típico de una comunidad rural (Guaygua et al., 2003: 299)».

El problema de este análisis (que por ciertos aspectos tiene puntos comunes con la tesis de la indigenización de la modernidad), es que no sale de los esquemas dicotómicos que se había propuesto superar: por último vuelve a aparecer la alusión negativa a las comunidades tradicionales consideradas como elementos que sobreviven a los cambios de época o de contexto ${ }^{13}$. En realidad, las costumbres socioculturales de dichas comunidades no se encuentran congeladas en una temporalidad inmóvil. Por ejemplo, los pescadores del lago Titicaca descritos por Bern Orlove (2002) ya no trabajan como hace cincuenta o incluso veinte años,

13 Mientras que los marxistas y los neoliberales, más allá de sus divergencias políticas, comparten la idea de que la introducción del mercado destruye a las sociedades tradicionales y a sus culturas, tanto los teóricos del comunitarismo indigenista como los poscoloniales de todos los países, consideran que las culturas tradicionales persisten bajo las degradaciones externas: después de algunos siglos de olvido y de ocultamiento, dichas culturas renacerían de las cenizas de la hegemonía occidental debido a la presión de la resistencia de los pueblos llamados «originarios». Todas esas teorías, se trate de destrucción o de resurgimiento, tienen la misma visión congelada de una cultura tradicional propia a los pueblos autóctonos. Este postulado está cuestionado por la teoría de la indigenización de la modernidad, formulada por Marshall Sahlins desde los años 1990: afirma que los esquemas culturales indígenas tienen la capacidad de apropiarse de la «modernidad capitalista» y que su continuidad se instala en el cambio. Para un análisis de estos temas, consultar el articulo de Alain Babadzan, 2009. 
debido no solo a la introducción de nuevas técnicas y materiales sino también al cambio del tipo de peces (trucha en los años 1930, pejerrey en los años 1970); consiguientemente, los modos de vida asociados a la pesca se han transformado. De la misma manera, trabajos de etnografía, etnohistoria o economía como los que realizan Michael Schulte, Olivia Harris y José Luis Ezaguirre (Schulte, 1999; Harris, 2000; Ezaguirre, 2005), muestran que las comunidades rurales no son hostiles a la moneda y a las relaciones comerciales por el hecho de venerar a una Pachamama dotada de bondad y de fertilidad, como la presentan los promotores actuales de la indianidad14. Por el contrario, la figura idílica de la Pachamama, cuyos atributos se acercan extrañamente mucho más a los de la Vírgen María que a las divinidades ambivalentes de las sociedades precoloniales, parecería más bien una invención reciente de intelectuales y agentes culturales «neo-indios» que se mueven en medios urbanos (Galinier \& Molinié, 2006).

Por tanto, habría que adoptar un punto de vista menos culturalista para estudiar la formación de las identidades alteñas de los migrantes. La encuesta realizada por Mario Yapu y su equipo (2008) sobre la juventud y la integración de los jóvenes aymaras muestra justamente que las identidades multiculturales observadas en El Alto son el reflejo, no solo de «culturas juveniles» sino de políticas públicas, tanto si se trata del liberalismo multicultural, impulsado a partir de los años 1990 o de la interculturalidad militante de fines de los años 2000. El surgimiento de demandas educativas, culturales y/o protestarias procede de los cuadros sociales forjados por dichos políticos. La encuesta se basa pues sobre tres grupos suficientemente distintos para ilustrar este cuadro conceptual: los grupos de hip hop aymara se levantan contra la «disciplina colonial», los movimientos de trabajadoras del hogar luchan por el reconocimiento de sus derechos, los aprendices de profesores de la Escuela Normal de profesores de primaria, persiguen un reconocimiento institucional y profesional. Si bien esos grupos tienen la voluntad de reapropiarse de una identidad indígena que ahora está valorizada socialmente, predomina en ellos el deseo de ascensión social sobre todo cuando el mercado de trabajo ofrece oportunidades que son mayores si los jóvenes son de la segunda (y no de la primera) generación de migrantes. Sin embargo, se producen transformaciones socioculturales y, gracias al impulso de las políticas del gobierno Morales, la identidad aymara que en el pasado podía parecer una identidad en retroceso, se está convirtiendo, por defecto, en objeto de una reivindicación sociocultural más positiva y más valorizante. En esta revelación de El Alto, se trata menos de una indigenización de la modernidad que de una relación especifica (imoderna?) con la tradición, siempre que se la considere como una reapropiación de las estructuras, no solo indígenas y campesinas, sino también mineras y sindicales en general que están al servicio de formas locales de organización o mejor aún de autoorganización. Esto permite librarse de la visión encantada y de la ficción

14 La etimología aymara de la palabra Pachamama no está ligada, por lo demás, a la noción de MadreTierra: pacha cubre un amplio campo semántico que incluye el ciclo del tiempo, del espacio y de la tierra mientras que mama tiene menos que ver con la noción de madre que con la de la autoridad que no es específicamente femenina. Para este tema, ver Harris, 2000. 
política de una ciudad construida por sus mismos habitantes para ver en ella el producto de la interacción entre varias series de factores: las transformaciones históricas del espacio urbano, en el que los procesos de segregación se ven redoblados por la ausencia de políticas urbanas y el entramado de esquemas culturales en el cual la producción de identidades depende menos de una continuidad con el pasado que de una relación con las formas de vida colectivas capaces de integrar diferentes influencias y donde las reivindicaciones de cara al Estado son una exigencia de reconocimiento por el Estado.

La ficción política de El Alto, funciona como una «reversión del estigma» destinada a erradicar los prejuicios contra una ciudad periférica, pobre y violenta. No es infundada en el sentido de que la acción de sus habitantes se debe a la vez a la ausencia relativa del Estado y a la ineficiencia de una gestión municipal que sufre de una falta de profesionales formados y de un clientelismo crónico. Constituye sin duda el orgullo de una población afligida por la precariedad, la pobreza y las formas de segregación social, espacial o cultural. Alto markaxa wali puq'antata jiwa jich'axa: El Alto se ha vuelto bien grande ahora, pueden decir los alteños (en aymara), refiriéndose no tanto al tamaño que a la nueva importancia política de la ciudad. Constituye tal vez el surgimiento de una ciudad de la cual se habla más de lo que ella misma habla: por esta razón, hay que superar la gloriosa historia de las insurrecciones recientes para que aparezcan las estructuras invisibles que producen, menos que una «politización de la etnicidad», una territorializacion de las identidades, y una transformación de la relación de los alteños a las culturas «tradicionales» e «indígenas». La ficción política de El Alto como ciudad aymara y rebelde corre el riesgo de que siga siendo el doble simbólico que impida ver la situación real de la población alteña, una referencia identitaria susceptible de ocultar las desigualdades no solo entre la ciudad y el resto de la sociedad, sino entre los residentes mismos de El Alto lo que podría confirmar lo dicho por Bourdieu, a saber, que las ficciones políticas cumplen también funciones sociales.

\section{Referencias citadas}

ABERCROMBIE, T., 2006 - Caminos de la memoria y del poder. Etnografía e historia en una comunidad andina, 630 pp.; La Paz: IFEA, IEB, Sierpe Publicaciones.

AGIER, M., 1992 - Ethnopolitique. Racisme, statuts et mouvement noir à Bahia. Cahiers d'études africaines, 32 (1), 125: 53-81.

ALBÓ X., 1999 - La Paz también es Chuquiyawu. In: La Paz Nuestra de Cada Día (H. Cajias, P. Contreras \& J. Orihuela, eds): 81-85; La Paz: PNUD.

ALBÓ, X., GREAVES, T. \& SANDOVAL, G., 1981-1986 - Chukiyawu. La cara aymara de La Paz; La Paz: Cipca, 4 tomos.

ALENDA, S., 1999 - Bolivie: Conciencia de Patria, une forme originale de clientélisme au sein d'un parti politique. Problèmes d'Amérique latine, $\mathbf{n} .^{\circ} \mathbf{3 2}$, janvier-mars: 99-114. 
ALVIZURI, V., 2009 - La construcción de la aymaridad. Una historia de la etnicidad en Bolivia (1952-2006), 354 pp.; Santa Cruz de la Sierra: Editorial El País.

ARBONA, J. M., en prensa - Apuntes sobre la historia de un «espacio vacío»: El Alto en la región metropolitana de La Paz.

BABADZAN, A., 2009 - L'«indigénisation de la modernité». La permanence culturelle selon Salhins. L'Homme, n. ${ }^{\circ}$ 190: 105-128.

BABY, V., 1995 - El Alto de La Paz, un bidonville d'altitude au coeur de l'Amérique latine; París: Universidad de Paris X bajo la dirección de Hervé Thery. Memoria para la obtención de un título de estudios avanzados (DEA).

BARRAGÁN, R., 1990 - Espacio Urbano y Dinámica Etnica: La Paz en el Siglo XIX, 307 pp.; La Paz: HISBOL.

BOUYSSE-CASSAGNE, T., HARRIS, O., PLATT, T. \& CERECEDA, V., 1987 - Tres reflexiones sobre el pensamiento andino, 231 pp.; La Paz: HISBOL.

CAJÍAS, F., BARRAGÁN, R., CAJÍAS, M., MEDINACELLI, X., 2007 - La Paz, Historia de contrastes, 265 pp.; La Paz: Fundación Nuevo Norte.

CÁMARA DEPARTAMENTAL DE INDUSTRIAS DE LA PAZ, 2004 - «Encuesta de necesidades de desarrollo empresarial en la industria manufacturera en la ciudad de El Alto».

CRESPO, C. \& SPRONG, S. (eds.), 2007 - Después de las guerras del agua, 245 pp.; La Paz: CESU-UMSS, Plural.

DEMÉLAS, M.-D. \& LAVAUD, J.-P., s.f. - El Alto n'est pas une banlieue misérable. En línea: http://www.aportescriticos.com.ar/potosi/El_Alto.html

DEMORAES, F., 1998 - Étude de l'évolution de l'agglomération de La Paz-El Alto depuis les vingt dernières années, compte tenu des contraintes environnementales du site. Une péjoration des conditions d'urbanisation ? Une base de référence : le Plan de Développement urbain de la ville de La Paz (1976-1977). Memoria de maestría en geografía realizada bajo la dirección del Sr. Robert D'Ercole.

DO ALTO, H., 2009-«ì Un gobierno de los movimientos sociales? Las nuevas configuraciones del poder político en los tiempos de Evo Morales».Comunicación presentada en el seminario internacional «Las reformas del Estado en los países andino-amazónicos. Poderes, territorios, sociedades», La Paz, 16 a 19 de junio de 2009: IFEA, PIEB, ILDIS, Cooperación regional, Embajada de Francia en Bolivia.

DUNKERKEY, J., 1984 - Rebellion in the Veins. Political Struggle in Bolivia (1952-1982); London: Verso.

ESCOBARI, L., 2005 - Caciques, Yanaconas, y Extravagantes: La Sociedad Colonial en Charcas s. XVI-XVIII, 307 pp.; La Paz: Plural.

EZAGUIRRE, J. L., 2005 - Composición de los ingresos familiares de campesinos indígenas. Un estudio en seis regiones de Bolivia; La Paz: CIPCA.

GALINIER, J. \& MOLINIÉ, A., 2006 - Les Néo-Indiens. Une religion du III millénaire, 330 pp.; París: Odile Jacob.

GARFIAS, S. \& MAZUREK, H., 2005 - El Alto desde una perspectiva poblacional, 150 pp.; La Paz: Codepo, IRD, USAID, Embajada de Francia en Bolivia.

GILL, L., 2000 - Teetering on the Rim, Global Restructuring, Daily Life and the Armed Retreat of the Bolivian State, 222 pp.; New York: Columbia University Press.

GUAYGUA, G., QUISBERT, M. \& RIVEROS, A., 2003 - The Presence of Aymara Traditions in Urban Youth Culture: Tales About the Multiculture of El Alto, Bolivia. In: Imaging the Andes: Shifting Margins of a Marginal World (T. Salman \& A. Zoomers, eds.): 288-300; Amsterdam: Aksant, Cedla. 
HARRIS. O., 2000 - To Make the Earth Bear Fruit: Ethnographic Essays on Fertility, Work and Gender in Highland Bolivia, 251 pp.; London: Institute of Latin American Studies.

HYLTON, F. \& THOMPSON, S., 2007 - Revolutionary Horizons: Past and Present in Bolivian Politics, 177 pp.; Londres: Verso.

KOESTER, G., 1976 - Estratificación socio-económica de las zonas de la ciudad de La Paz.

LAZAR, S., 2008 - El Alto, Rebel City. Self and Citizenship in Andean Bolivia, 328 pp.; Durham \& London: Duke University Press.

MEDINACELLI, X., 2009 - Los orígenes multiculturales de La Paz, 101 pp.; La Paz: Santillana de Ediciones S.A.

MILLER, S. W., 2007 - An Environmental History of Latin America, 257 pp.; New York: Cambridge University Press.

ORLOVE, B., 2002 - Lines in the Water. Nature and Culture at Lake Titicaca, 287 pp.; Berkeley: University of California Press.

PAERREGAARD, K., 2003 - Andean Predicaments: Cultural Reinvention and Identity Creation Among Urban Migrants in Peru. In: Imaging the Andes : Shifting Margins of a Marginal World (T. Salman \& A. Zoomers, eds.): 272-287; Amsterdam: Aksant, Cedla.

POUPEAU, F., 2008 - Les structures spatiales des inégalités. Éléments de méthode pour une analyse des recompositions de l'espace social; París: universidad de Paris I Panthéon Sorbonne. Tesis de postgrado para la habilitación a dirigir investigaciones (HDR), defendida el 21 de noviembre de 2008, bajo la dirección de AnneCatherine Wagner (tribunal integrado por Eric Brian, Alain Chenu, Olivier Dabène, Bruno Lautier, Catherine Rhein y Anne-Catherine Wagner).

POUPEAU, F., 2010 - De la migración rural a la movilidad intra-urbana. Una perspectiva sociológica sobre las desigualdades socio-espaciales de acceso al agua en El Alto. In: Modelos de gestión del agua en los Andes (F. Poupeau \& C. Gonzáles Andrícain, eds.): 243-280; La Paz/Lima: IFEA, PIEB, Plural Editores.

QUISPE VILLCA, M. A., 2004 - De ch'usa marka a jach'a marka. De pueblo vacío a pueblo grande. Pequeñas historias contadas desde el alma misma de El Alto, 147 pp.; La Paz: Plural Editores, Wayna Tambo.

RIVERA, S., 1978 - La expansión del latifundio en el altiplano Boliviano: elementos para la caracterización de una oligarquía regional. Avances, n. ${ }^{\circ}$ 2: 95-118.

SAHLINS, M., 2007 - La découverte du vrai sauvage, et autres essais, 456 pp.; París: Gallimard,.

SAIGNES, T., 1992 - De los ayllus a las parroquias de índice: Chuquiago y La Paz. In: Ciudades de los Andes: Visión Histórica y Contemporánea (E. Kingman, ed.): 53-91; Quito: IFEA, Ciudad.

SANDOVAL, G. \& SOSTRES, F., 1989 - La ciudad prometida. Pobladores y organizaciones sociales en El Alto; La Paz: Editorial Sistema/ILDIS.

SCHULTE, M., 1999 - Llameros y caseros. La economía regional kallawaya, 323 pp.; La Paz: PIEB.

SPRONG, S., 2007 - The Politics of Third World Water Privatization: Neoliberal Reform and Popular Resistance in Cochabamba and El Alto, Bolivia; Toronto (Ontario): York University. Graduate Program in Political Science, Dissertation Submitted to the Faculty of Graduate Studies in partial fulfillment requirements for the degree of Doctor of Philosophy.

THOMSON, S., 2003 - We Alone Will Rule: Native Andean Politics in the Age of Insurgency, 399 pp.; Madison: University of Wisconsin. 
El Alto: una ficción política

YAÑEZ, P. \& LANDA, F., 2007 - Informe Especial. Informalidad en el Mercado Laboral; La Paz: UDAPE.

YAPU, M. et al., 2008 - Jóvenes aymaras, sus movimientos, demandas y políticas públicas; La Paz/Río de Janeiro: Universidad para la Investigación Estratégica en Bolivia, Instituto Brasileño de Análisis Social y Económico.

ZAVALETA, R., 1986 - Lo nacional-popular en Bolivia, 276 pp.; Mexico: Siglo Veintiuno Editores. 